\title{
Gestão da Ciência, Tecnologia e Inovação: As perspectivas do Brasil face ao contexto internacional
}

Roberto Sbragia

Professor Titular do Departamento de Administração da FEA/USP- Faculdade de Economia, Administração e Contabilidade da Universidade de São Paulo. Doutor, Mestre e Bacharel em Administração pela Universidade de São Paulo, com PósDoutorado em Management of R\&D pela Northwestern University. Pesquisa nas áreas de Política e Gestão da Inovação Tecnológica e de Gerenciamento de Projetos.

rsbragia@usp.br

Natan de Souza Marques

Doutorando do Programa de Pós-graduação em Administração (PPGA) da FEA/USP- Faculdade de Economia, Administração e Contabilidade da Universidade de São Paulo. Mestre em Administração pela Universidade de São Paulo e Bacharel em Administração pela Universidade Federal da Bahia (UFBA). Pesquisa nas áreas de Gestão de Inovação e Empreendedorismo.

natanmarques@usp.br

Aline Mariane de Faria

Doutoranda do Programa de Pós-graduação em Administração (PPGA) da FEA/USP- Faculdade de Economia, Administração e Contabilidade da Universidade de São Paulo. Mestre em Administração pela Universidade de São Paulo e Bacharel em Administração pela FAI - Centro de Ensino Superior em Gestão, Tecnologia e Educação. Pesquisa na área de Gestão da Inovação e Financiamento para Inovação.

alinefaria@usp.br

\section{Editor Científico: José Edson Lara}

Organização Comitê Científico

Double Blind Review pelo SEER/OJS

Recebido em 10.05.2017

Aprovado em 12.06.2017

Este trabalho foi licenciado com uma Licença Creative Commons - Atribuição - Não Comercial 3.0 Brasil
} 


\section{RESUMO}

Economias globais aliadas a mercados dinâmicos e complexos têm lançado às nações uma demanda por pro-atividade na busca da vantagem competitiva, característica que impulsiona o crescimento econômico e torna uma nação competitiva no cenário mundial. Alcançar vantagem competitiva, no entanto, exige esforços direcionados para Políticas de Gestão da Ciência, Tecnologia e Inovação, as quais, se bem implementadas, permitem a construção de Sistemas Nacionais de Inovação (SNI) fortes, facilitando a formação de empresas inovadoras. O presente artigo, a partir de dados secundários, analisa as perspectivas do Brasil face ao contexto internacional no tocante aos indicadores de Ciência, Tecnologia e Inovação, o perfil de suas empresas inovadoras e o papel da gestão nesse ambiente. As conclusões indicam que o país, embora um dos ainda mais ativos no continente latino-americano, não conseguiu ainda uma posição de destaque como inovador. Vários fatores contribuem para esse posicionamento, como abaixa interação entre Governo, Universidades e Empresas como peças harmonicamente atuantes e a falta de incentivos fiscais atraentes e de fácil uso. Por fim, empresas inovadoras requerem práticas de gestão que aliem a capacitação à inovação, e desta à competitividade, numa autentica inovação de valor.

Palavras-chaves: Competitividade das Nações, Sistema Nacional de Inovação; Cooperação para Inovação; Gestão da Inovação na Empresa.

\section{ABSTRACT}

Global economies allied to dynamic and complex markets have demanded nation' proactivity in the pursuit of competitive advantage, a characteristic that drives economic growth and makes a nation competitive in the world scenario. Achieving competitive advantage, however, requires efforts focused on Science, Technology and Innovation Policies, which, if well implemented, allow the construction of strong National Innovation Systems (SNI), facilitating the consolidation of innovative companies. This article, based on secondary data, analyzes the perspectives of Brazil against the international context in relation to the indicators of Science, Technology and Innovation, the profile of its innovative companies and the role of management in this environment. Findings indicate that the country, although one of the most active in the Latin American continent, has not yet achieved a prominent position as an innovator. Several factors contribute to this position, as the low interaction between Government, Universities and Companies and the low attractiveness of financial incentives oriented to innovation. Finally, innovative companies require excellent management practices to be able to link innovation to competitiveness in an authentic innovation with value to business.

Keywords: Nation Competitiveness, National Innovation System; Cooperation for Innovation; Innovation Management at the Firm Level. 


\section{RESUMEN}

Las economías globales aliadas a mercados dinámicos y complejos han lanzado a las naciones una demanda por pro-actividad en la búsqueda de la ventaja competitiva, característica que impulsa el crecimiento económico y hace una nación competitiva en el escenario mundial. Alcanzar ventaja competitiva, sin embargo, exige esfuerzos dirigidos a Políticas de Gestión de la Ciencia, Tecnología e Innovación, las cuales, si bien implementadas, permiten la construcción de Sistemas Nacionales de Innovación (SNI) fuertes, facilitando la formación de empresas innovadoras. El presente artículo, a partir de datos secundarios, analiza las perspectivas de Brasil frente al contexto internacional en cuanto a los indicadores de Ciencia, Tecnología e Innovación, el perfil de sus empresas innovadoras y el papel de la gestión en ese ambiente. Las conclusiones indican que el país, aunque uno de los aún más activos en el continente latinoamericano, no logró aún una posición de destaque como innovador. Hay diversos factores que han contribuido para ese posicionamiento, entre los cuales la baja interacción entre Gobierno, Universidades e Empresas y la falta de incentivos fiscales atrayentes y de fácil uso. Por último, empresas innovadoras requieren prácticas de gestión que ubiquen la capacitación a la innovación, y de ésta a la competitividad, en una auténtica innovación de valor.

Palabras claves: Competitividad de las Naciones, Sistema Nacional de Innovación; Cooperación para la innovación; Gestión de la innovación en la empresa.

\section{Introdução}

Economias globais aliadas a mercados dinâmicos e complexos têm lançado às nações uma demanda por pro-atividade na busca da vantagem competitiva, característica que impulsiona o crescimento econômico e torna uma nação competitiva no cenário mundial. Alcançar vantagem competitiva, no entanto, exige esforços direcionados para Políticas de Gestão da Ciência, Tecnologia e Inovação, as quais, se bem implementadas, permitem a construção de Sistemas Nacionais de Inovação (SNI) fortes, facilitando a criação e o desenvolvimento de empresas inovadoras. Nesse sentido, busca-se com o presente artigo analisar as perspectivas do Brasil face ao contexto internacional no tocante a alguns indicadores de Ciência, Tecnologia e Inovação, as características das empresas industriais inovadoras situadas no país, assim como o papel da gestão enquanto função facilitadora na busca de resultados inovadores por parte das empresas.

Nesse sentido, o artigo está estruturado, além dessa introdução, em quatro outras seções. Na seção 2 aborda-se o Sistema Nacional de Inovação, apresentando o posicionamento dos países no mundo e na América Latina, 
apontando para a posição e relevância do Brasil nesse contexto. Na seção três é abordada a Inovação na Indústria Brasileira, tratando de aspectos como o perfil dos dispêndios das empresas com atividades de inovação; panorama das empresas industriais inovadoras no Brasil; políticas públicas e incentivos à inovação; e cooperação universidade-empresa. Na seção quatro, são abordadas características da gestão da inovação a partir da perspectiva da empresa. Por fim, são apresentadas as conclusões e considerações finais do trabalho.

\section{Sistemas Nacionais de Inovação}

Um Sistema Nacional de Inovação- SNI é uma construção institucional que impulsiona o progresso tecnológico em economias capitalistas. Esses arranjos institucionais envolvem empresas, redes de empresas, universidades, institutos de pesquisa, instituições financeiras agências governamentais que se articulam com o objetivo de desenvolver, implementar e difundir inovações em uma nação (Albuquerque, 1996).

Um SNI bem estruturado é crucial para alavancar o desenvolvimento sustentável de um país. Nesse sentido, uma vez que o objetivo do Estado é promover ações de interesse público para a promoção do desenvolvimento econômico e social (Muller, 2003), é justificável que o governo promova políticas para induzir a transformação da economia por meio da inovação. Para que essas políticas tenham impactos realmente relevantes, são necessários estudos que analisem as peculiaridades de um determinado SNI. Com isso em mente, é possível identificar caminhos para que as ações públicas de países com SNIs menos desenvolvidos possam promover o crescimento econômico, com base em benchmarking das ações dos países com SNIs maduros e desenvolvidos.

Embora sujeitos a inegáveis limitações metodológicas, os indicadores de inovação à nível de país são hoje a principal fonte de dados para a análise e avaliação dos chamados sistemas nacionais de inovação (Cavalcante \& De Negri, 2011). Desta forma, esse capítulo objetiva apresentar e analisar os principais indicadores de inovação em nível país de algumas nações selecionadas, afim de amparar um cenário atual para discussão. 


\subsection{Indicadores de Inovação}

Com o intuito de identificar tais indicadores de inovação à nível país, surveys têm sido realizados em várias nações desde a década de 1990, como é o caso do (i) Community Innovation Survey (CIS) que é o instrumento utilizado pela União Européia, e a (ii) coleta realizada pela Rede Iberoamericana e Interamericana de Indicadores de Ciência, Tecnologia e Inovação (RICYT na sigla em espanhol), na qual participam todos os países da América Latina, Caribe, América do Norte, Portugal e Espanha.

Especialmente no Brasil, os surveys de inovação passaram a ser produzidos a partir de 2000, quando foi lançada a primeira edição da Pesquisa de Inovação Tecnológica (PINTEC), desenvolvida a cada três anos pelo Instituto Brasileiro de Geografia e Estatística (IBGE). A PINTEC segue, em linhas gerais, as diretrizes do Manual de Oslo, da mesma forma como outros surveys internacionais (IBGE, 2015).

Embora amplamente disseminados, o uso dos surveys de inovação possui limitações metodológicas relevantes, especialmente entre os indicadores de resultado (ver Cavalcante \& De Negri, 2011). Em virtude dessas dificuldades metodológicas, os indicadores de esforço são muitas vezes considerados medidas mais usuais. Com isso, o gasto em P\&D como porcentagem do PIB permanece no centro dos debates sobre as políticas públicas de CT\&I, seja nos países da Organização para a Cooperação e Desenvolvimento Econômico (OCDE), seja em países como o Brasil (Cavalcante \& De Negri, 2011).

Tendo isso em mente, a discussão a seguir levará em consideração, essencialmente tais indicadores de esforço, como gastos total de CTI no país, percentagem dos gastos de CTI com relação ao PIB. Em alguns momento mencionar-se-ão dados de solicitação de patentes, além da própria taxa de inovação, que é o indicador de resultado, em complemento ao de esforço, mais usado. 


\subsection{Contexto Internacional}

Estima-se que os investimentos globais em P\&D alcançarão \$2,066 trilhões em paridade de poder de compra (\$PPC ${ }^{1}$ ) em 2017, algo que representa um aumento de 3,4\% em relação ao ano de 2016, considerando uma amostra de 116 países selecionados (IRI, 2017).

\section{Tabela 1}

Participação do investimento global em P\&D, por região

\begin{tabular}{|c|c|c|c|}
\hline Países & $\begin{array}{l}2015 \\
\text { (real) }\end{array}$ & $\begin{array}{l}2016 \\
\text { (estimado) }\end{array}$ & $\begin{array}{l}2017 \\
\text { (previsão) }\end{array}$ \\
\hline Ásia (24 países) & $41,80 \%$ & $42,30 \%$ & $42,90 \%$ \\
\hline China & $19,40 \%$ & $20,10 \%$ & $20,80 \%$ \\
\hline $\begin{array}{l}\text { América do Norte (12 } \\
\text { países) }\end{array}$ & $27,90 \%$ & $27,80 \%$ & $27,70 \%$ \\
\hline Estados Unidos & $25,80 \%$ & $25,60 \%$ & $25,50 \%$ \\
\hline Europa (34 países) & $21,60 \%$ & $21,20 \%$ & $20,80 \%$ \\
\hline Rússia/CAS (5 países) & $3,00 \%$ & $2,90 \%$ & $2,80 \%$ \\
\hline Oriente Médio (13 países) & $2,50 \%$ & $2,40 \%$ & $2,50 \%$ \\
\hline América do Sul (10 países) & $2,70 \%$ & $2,50 \%$ & $2,40 \%$ \\
\hline África (18 países) & $1,00 \%$ & $0,90 \%$ & $0,90 \%$ \\
\hline Total (116 países) & $100,00 \%$ & $100,00 \%$ & $100,00 \%$ \\
\hline
\end{tabular}

Fonte: Spending, D., \& Bernstein, E. (2017). Global R \& D Funding Forecast. R\&D Magazine, (Winter), 1-36. Retrieved from

http://digital.rdmag.com/researchanddevelopment/2017_global_r_d_funding_forecas

Conforme pode-se observar no Tabela 1 em uma avaliação internacional, os Estados Unidos é o país com os maiores investimentos em P\&D (25,5\% do montante de investimento global), um título que ocupou nos últimos 50 anos (IRI, 2017). Essencialmente, esse país é considerado inovador graças ao seu mercado financeiro sofisticado e alta intensidade nas atividades de capitais de risco, o que ajuda a estimular as atividades do setor privado. Os pontos fortes dos EUA também incluem a presença de universidades e empresas de alta qualidade com atividades globais de P\&D, a qualidade das publicações científicas, bem como o desempenho de seus polos de inovação (WIPO, 2012). Além disso, os EUA investem 2,83\% de todo seu PIB em P\&D (ver quadro $x$ ), muito acima da média mundial que é de 1,72\% (IRI, 2017).

\footnotetext{
${ }^{1}$ \$ PPC reflete melhor o valor real dos investimentos e permite uma maior comparabilidade, eliminando diferenças nos níveis de preços entre os países. Essencialmente, isso significa que uma soma de dinheiro convertida em dólares norte-americanos às taxas PPP comprará a mesma cesta de bens e serviços em todos os países (IPEA, 2011).
} 
Contudo, embora seja o país com maior investimento bruto em P\&D, a participação dos EUA no investimento global tem diminuído devido às altas taxas de crescimento dos países da Ásia, com destaque para a China. Os investimentos chineses em P\&D cresceram 7\% em 2016 e 2017, algo bem maior que as taxas dos EUA e Europa, que estão na faixa de $2 \%$ a $3 \%$ (IRI, 2017). Esse resultado é reflexo da sofisticação empresarial chinesa. Em 2016, a China apresentou fortes desempenhos em vários indicadores, entre os quais (i) a presença de empresas de P\&D global, (ii) pesquisadores de alta qualidade na área de empreendimentos comerciais, (iii) pedidos de registro de patentes e outras variáveis relacionadas com a propriedade intelectual (WIPO, 2012).

No que diz respeito ao Índice Global de Inovação², em 2016 a China tornouse a primeira economia de rendimento médio a figurar entre as 25 nações mais inovadoras do mundo. Paralelamente, um grupo de economias asiáticas, que inclui Indonésia, Malásia, Singapura, Tailândia, Filipinas e Vietnã, tem feito um grande esforço em prol do aperfeiçoamento dos seus ecossistemas de inovação e da conquista de uma posição elevada em certo número de indicadores relacionados com a educação, $P \& D$, crescimento da produtividade e de exportações de produtos de alta tecnologia (Cornell University, INSEAD, \& WIPO, 2017).

O resto do mundo (Rússia/CAS, África, América do Sul e países do Oriente Médio) representam uma combinação de $8,6 \%$ dos investimentos globais em P\&D com crescimento médio combinado de apenas de 1,5\% ao ano (IRI, 2017). Entre essas regiões de menor representatividade, apenas cinco países têm investimentos em P\&D superiores a $1 \%$ do seu PIB. Brasil e Rússia dominam suas respectivas regiões em termos de gastos em P\&D. Já no Oriente Médio, as despesas de P\&D são mais distribuídas entre o Irã, Israel, Qatar e Arábia Saudita que, em conjunto, contribuem com $88,9 \%$ do gasto em P\&D da região. Da mesma forma, a África do Sul, o Egito e a Nigéria contribuem juntos com $65,7 \%$ dos gastos totais de P\&D da África (IRI, 2017).

\footnotetext{
2 Índice que estuda diversos indicadores, desde registros de patentes, despesas em educação, instrumentos de financiamento, entre outros, para construir um ranking de inovação (GII, 2017).
} 


\section{Tabela 2}

Investimento em P\&D como percentagem do PIB

\begin{tabular}{cllllr}
\hline $\begin{array}{c}\text { Posição } \\
2017\end{array}$ & \multicolumn{1}{c}{ País } & $\begin{array}{c}\mathbf{2 0 1 7} \\
\text { Previst } \\
\mathbf{0}\end{array}$ & $\begin{array}{c}\text { Posiçã } \\
\mathbf{0} \\
\mathbf{2 0 1 7}\end{array}$ & \multicolumn{1}{c}{ País } & $\begin{array}{c}\mathbf{2 0 1 7} \\
\text { Previsto }\end{array}$ \\
\hline 01 & Coréia do Sul & $4,29 \%$ & 21 & Reino Unido & $1,75 \%$ \\
02 & Israel & $4,10 \%$ & 22 & Noruega & $1,75 \%$ \\
03 & Japão & $3,50 \%$ & 23 & Irlanda & $1,75 \%$ \\
04 & Finlândia & $3,50 \%$ & 24 & Rússia & $1,50 \%$ \\
05 & Suécia & $3,30 \%$ & 25 & Itália & $1,27 \%$ \\
06 & Dinamarca & $3,04 \%$ & 26 & Espanha & $1,27 \%$ \\
07 & Áustria & $3,00 \%$ & 27 & Malásia & $1,25 \%$ \\
08 & Suíça & $2,98 \%$ & 28 & Brasil & $1,20 \%$ \\
09 & Alemanha & $2,84 \%$ & 29 & Peru & $0,92 \%$ \\
10 & Estados Unidos & $2,83 \%$ & 30 & Polônia & $0,90 \%$ \\
11 & Singapura & $2,60 \%$ & 31 & África do Sul & $0,85 \%$ \\
12 & Catar & $2,50 \%$ & 32 & Índia & $0,84 \%$ \\
13 & Taiwan & $2,45 \%$ & 33 & Irã & $0,75 \%$ \\
14 & Bélgica & $2,35 \%$ & 34 & Bangladesh & $0,70 \%$ \\
15 & Austrália & $2,30 \%$ & 35 & Egito & $0,60 \%$ \\
16 & França & $2,24 \%$ & 36 & Paquistão & $0,60 \%$ \\
17 & Países Baixos & $2,10 \%$ & 37 & Argentina & $0,56 \%$ \\
18 & China & $1,96 \%$ & 38 & México & $0,50 \%$ \\
19 & República & $1,85 \%$ & 39 & Arábia & $0,45 \%$ \\
& Checa & & & Saudita & \\
20 & Canadá & $1,80 \%$ & 40 & Indonésia & $0,30 \%$ \\
\hline
\end{tabular}

Fonte: Spending, D., \& Bernstein, E. (2017). Global R \& D Funding Forecast. R\&D Magazine, (Winter), 1-36. Retrieved from

http://digital.rdmag.com/researchanddevelopment/2017_global_r_d_funding_forecas

\subsection{Contexto da América Latina e Caribe}

Com base no levantamento feito pela Rede Iberoamericana e Interamericana de Indicadores de Ciência, Tecnologia e Inovação (RICYT), embora o investimento em P\&D esteja crescendo entre os países da América Latina e Caribe nos últimos anos, a região contribui com apenas $3,5 \%$ do total do investimento mundial (RICYT, 2015). Somado à isso, $89 \%$ de todo o investimento em $P \& D$ dessa região deriva de apenas três países, fato que demonstra a alta centralização desses recursos: Brasil (63,9\%), México (17,4\%) e Argentina (7,6\%). Embora esses dados sejam referentes ao ano de 2014, pouco antes do ápice da crise brasileira, que refletiu em uma queda acentuada nos investimentos em P\&D, especialmente aqueles de origem pública, percebe-se a grande hegemonia brasileira na América Latina e Caribe no que diz 
respeito à investimento em inovação. Essa centralização se repete quando é analisado o número de pesquisadores na região. Embora a quantidade de pesquisadores tenha aumentado nos últimos anos, 90\% deles estão no Brasil, México e Argentina. O contrassenso, no entanto, está em um aumento de apenas $2 \%$ na publicação de artigos científicos e, também, na prevalência de solicitações de patentes feitas por não residentes, que, em 2015 , representaram $84,4 \%$ do total de solicitações em toda região (RICYT, 2015).

Além disso, no que diz respeito às despesas de $P \& D$ discriminadas por fonte de fundos ${ }^{3}$, a maioria dos países da América Latina depende fortemente do financiamento por parte de seus governos, diferentemente de países com SNIs bem desenvolvidos ,como Estados Unidos e Japão, com mais de $60 \%$ do financiamento de P\&D vindo de empresas (Unesco, 2017).

Quanto ao Índice Global de Inovação na América Latina e Caribe, o país mais

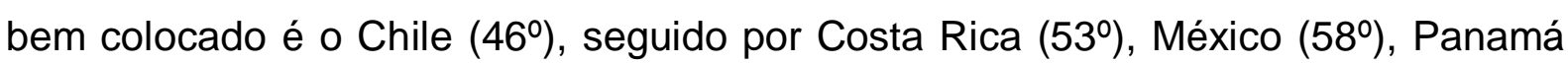

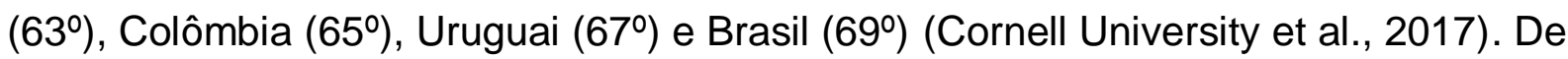
forma geral, as classificações do Índice Global de Inovação desta região não têm registrado progressos significativos, relativamente a outras regiões, e nenhum de seus países mostra desempenhos notáveis em matéria de inovação (Cornell University et al., 2017).

Como pontos positivo, entre as principais economias da região (Argentina, Brasil, Chile, Colômbia e México) há o registro de bons desempenhos nas áreas do capital humano e de pesquisa, tais como a qualidade de suas universidades, matrículas em educação superior e presença de empresas globais de P\&D, assim como em matéria de tecnologia da informação e das comunicações (Cornell University et al., 2017).

De qualquer forma, os indicadores regionais de inovação refletem a imaturidade dos sistemas nacionais dos países latino-americanos, cujos investimentos em P\&D estão totalmente ligados às perspectivas macroeconômicas $\mathrm{e}$ não são vistos como um vetor para retomar o crescimento ou para manter níveis constantes dos mesmos (Carvalho \& Furtado, 2017). No entanto, é notável que existe potencial para uma ampla melhoria regional da inovação, tanto em termos de

\footnotetext{
${ }^{3}$ Refere-se ao total de despesas bruta em P\&D durante um determinado período, financiado por diferentes setores da economia (empresa comercial, governo, ensino superior, organizações privadas sem fins lucrativos e instituições do exterior) expresso em percentagem.
} 
desempenho geral da inovação como também de variáveis-chave de inovação, tais como publicações científicas e patentes (Cornell University et al., 2017). Para tanto alcançar tal potencial são necessários mais investimentos em inovação e em sistemas de inovação mais coordenados (Cornell University et al., 2017).

A seguir são apresentadas particularidades dos principais países dessa região: Chile (país mais inovador da região pelo GIl), Argentina, Peru, Colômbia, México e Brasil (países com maiores montantes de investimento).

\subsubsection{Chile}

O Chile tem atravessado um prolongado e fraco crescimento econômico por conta da baixa da demanda interna, associada a uma queda nos investimentos (Banco Central de Chile, 2017). Ainda assim, o Chile é considerado a nação mais inovadora da América Latina e Caribe pela classificação do Índice Global de Inovação, ocupando a 46 ${ }^{\mathrm{a}}$ posição no mundo (Cornell University et al., 2017). Os investimentos em P\&D do país cresceram 57,3\% entre 2010 e 2015, chegando ao valor de $\$ 1.617,28$ milhões em paridade de poder de compra (\$ PPC) e representando $0,38 \%$ de seu PIB (RICYT, 2015).

Como na maioria dos países da América Latina e Caribe, o Chile tem o governo como principal financiador da atividade inovativa, respondendo por $42,6 \%$ de todo o valor (RICYT, 2015). Nessa perspectiva é interessante citar que a política governamental chilena tem priorizado as pequenas e médias empresas (PMEs). $12,2 \%$ de todas as PMEs inovadoras ${ }^{4}$ chilenas recebem apoio governamental, contra $5,4 \%$ de todas as grandes empresas inovadoras com suporte governamental (OECD, 2015).

Destaca-se ainda uma das características mais iminentes do país, que é sua qualidade acadêmica voltada para a pesquisa. Em 2014, dos pesquisadores do país, $45 \%$ doutor eram doutores (RICYT, 2015).

\footnotetext{
${ }^{4}$ Empresas inovadoras em produto e/ou processo, incluindo atividades de inovação abandonadas ou em andamento (independentemente da inovação organizacional ou de marketing) (OCDE, 2015).
} 


\subsubsection{Argentina}

A Argentina é o $2^{\circ}$ da América Latina em termos de investimento em P\&D em relação ao PIB (média de 0,6\% entre 2010 e 2015), e é o 3o país que mais contribui com o investimento total da região, com \$5.555,59 milhões em paridade de poder de compra (\$ PPC) em 2015, sendo que, deste valor, $76,4 \%$ foi financiado pelo governo (RICYT, 2015). Contudo, a distribuição desses investimentos não é equilibrada. Existe uma concentração na região metropolitana de Buenos Aires $(33,9 \%)$, Ciudad de Buenos Aires $(26,8 \%$,$) Córdoba (8,12 \%)$ e Santa Fé $(5,01 \%)$ (MCTIP, 2015).

Quanto à solicitação de patentes, foram um total de 4125 em 2015, sendo $86,77 \%$ de não residentes. Esse valor representa $6,11 \%$ de todas solicitações da América Latina, estando atrás apenas do Brasil e do México (RICYT, 2015). A área de estudo que tem se destacado é a "química, petroquímica e carboquímica", que implicou $37,2 \%$ das patentes e modelos de utilidades solicitados em 2014, seguida pela área de "desenvolvimento industrial e tecnológico", com 22,1\% (MCTIP, 2015).

Outro ponto positivo é que a Argentina possui 4,72 pesquisadores por cada 1.000 pessoas economicamente ativas, sendo o maior valor entre os países da América Latina e Caribe ${ }^{5}$ (RICYT, 2015). Eram 83.837 pesquisadores em 2014, respondendo por $17,7 \%$ dos pesquisadores de toda região. Destes, cerca de $30,7 \%$ são doutores e 11,11\% são mestres (RICYT, 2015).

\subsubsection{Peru}

A economia peruana registrou um crescimento contínuo nos últimos anos. Em 2016, apesar do fraco momento nos países vizinhos, o crescimento foi $3,9 \%$. A principal causa para esse crescimento é o aumento da produção de cobre e os investimentos na expansão das minas. Só o setor minerador e de hidrocarbonetos cresceu 16,3\% em 2016.

Ainda que sua economia tenha boas perspectivas, o cenário da inovação provê fracos indicadores. Em 2015, o país investiu nas atividades ligadas à inovação um valor igual à \$461,48 milhões em paridade de poder de compra (\$ PPC), algo

\footnotetext{
${ }^{5}$ Considerando países com dados disponíveis.
} 
que representou apenas $0,6 \%$ de todo investimento da América Latina e Caribe. Além disso, o valor de seu investimento importou apenas $0,12 \%$ de seu PIB, indicador muito abaixo da média da região que é $0,70 \%$ (RICYT, 2015).

O baixo investimento é aliado a um sistema educacional que não acompanha as demandas nacionais, nem para a P\&D tecnológica, nem para as atividades de produção. Com isso, não há massa crítica em áreas de interesse nacional. Enquanto a América Latina e Caribe possuem 1,57 pesquisadores para cada 1.000 pessoas economicamente ativas, o Peru possui apenas 0,2 pesquisadores (RICYT, 2015).

No que diz respeito ao Índice Global de Inovação, o país ocupa a 70ª posição, logo após o Brasil (69a). A melhor posição peruana no estudo recai no indicador de

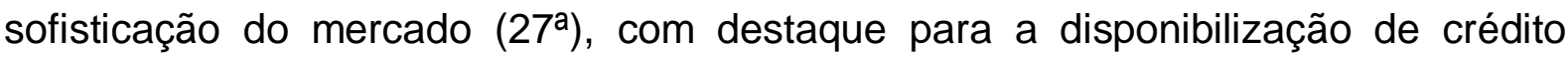
$\left(15^{\mathrm{a}}\right)$.

\subsubsection{Colômbia}

A Colômbia, país que ocupa a $4^{a}$ posição na América Latina e Caribe no Índice Global de Inovação (65a no mundo), investiu \$1.914,66 milhões em paridade de poder de compra (\$ PPC) (RICYT, 2015). Embora esse valor seja aparentemente pequeno, o país tem evoluído bastante. No ano de 2010 , o país investiu $\$ 929,53$ milhões em paridade de poder de compra (\$ PPC), algo que representou um aumento de $106 \%$ no período. No tocante ao investimento como percentual do PIB, a relação também foi positiva de 2010 para 2015. Em 2010 o país investia 0,19\% de seu PIB em inovação e em 2015 esse valor passou para 0,29\%. Ainda assim, seu investimento contribui com apenas $2,8 \%$ do total da América Latina e Caribe (RICYT, 2015).

Como aspectos positivos, cabe destacar que o país foi considerado o $2^{\circ}$ com a maior facilidade de obtenção de crédito no mundo (Gll, 2017), algo que pode ser útil para alavancar o desenvolvimento da região. Além disso, diferentemente de países vizinhos, o governo da Colômbia impulsiona os investimentos de P\&D mesmo em tempos de crise, visando compensar o investimento privado mais baixo. Ainda assim, em 2015, o setor privado financiou $47 \%$ dos gastos com P\&D, enquanto o governo financiou 33\% (RICYT, 2015).

Ademais, o país possui relativamente poucos pesquisadores $(0,5$ Investigadores cada 1000 pessoas economicamente ativas). Contudo, esses 
pesquisadores possuem formação mais alta que a média da região: $75 \%$ dos pesquisadores colombianos são mestres ou doutores (RICYT, 2015).

\subsubsection{México}

Com importantes recursos minerais e petrolíferos (IRI, 2016), o México contribui ativamente para as cadeias de valor globais, inclusive em setores de alta tecnologia (Cornell University et al., 2017). Contudo, a intensidade de P\&D do México enfraqueceu por mais de 20 anos (IRI, 2016), algo que pode ser ainda mais agravado com os possíveis efeitos adversos das políticas protecionistas do governo do presidente dos EUA, Donald Trump (Banco de México, 2007). Prova disso é seu baixo investimento nacional em P\&D, \$11,63 bilhões em paridade de poder de compra (\$ PPC), representando apenas $0,5 \%$ do PIB em $2017^{6}$. Em contrapartida, o investimento em P\&D feito pelo México respondeu por $17,4 \%$ de todo investimento da América Latina em 2015, sendo o $2^{\circ}$ mais representativo da região, perdendo apenas para o Brasil (RICYT, 2015).

Embora o setor governamental financie a maioria do investimento em P\&D no país, 70,26\% em 2015 (RICYT, 2015), apenas 21,8\% das empresas inovadora ${ }^{7}$ mexicanas receberam de fato apoio governamental (OECD, 2015), reafirmando que o país mostrou relativamente poucos incentivos políticos, além de uma infraestrutura acadêmica não adequada para apoiar o crescimento de P\&D (IRI, 2016).

Além disso, falta pessoal capacitado para trabalhar em C\&T, especialmente em áreas de pesquisa e desenvolvimento tecnológico, e particularmente no setor produtivo. O México possui uma comunidade de pesquisadores pequena, $42.223 \mathrm{em}$ 2013 (RICYT, 2015). Distante da realidade de países desenvolvidos, como Espanha $(9,35)$ e Portugal $(15,59)$, o México possui 0,84 investigadores para cada 1000 indivíduos de sua população economicamente ativa, valor muito abaixo da média da própria América Latina que é de 1,57 (RICYT, 2015).

\footnotetext{
${ }^{6}$ Previsto

7 Empresas inovadoras em produto e/ou processo, incluindo atividades de inovação abandonadas ou em andamento (independentemente da inovação organizacional ou de marketing) (OCDE, 2015).
} 


\subsubsection{Brasil}

O Brasil é o país que mais contribui com o investimento total em P\&D da América Latina e Caribe (63,9\%) (RICYT, 2015). Estima-se que o país feche 2017 com um investimento de US $\$ 37,2$ bilhões em P\&D, (1,8\% do total global em 2017) valor que representa $1,2 \%$ do seu PIB, indicador que permaneceu bastante estável nos últimos seis anos (IRI, 2016).

Contudo, o panorama da inovação no país mudou de otimismo para preocupação em sete anos. Em 2011, ocupava a 47 posição no Índice Global de Inovação, mas caiu para a 69a em 2016 e em 2017. Mesmo sendo a maior economia da América Latina e do Caribe, o Brasil ocupa apenas a $7^{\underline{a}}$ posição no ranking regional entre 18 países (Cornell University et al., 2017).

Isso ocorre principalmente devido à fraca infraestrutura tecnológica do Brasil, com um sistema educacional pobre, na qual a educação básica e média é precária, algo que reflete na falta de pessoal tecnológico na indústria e academia. Há apenas 1,48 pesquisadores por 1.000 empregos totais (OECD, 2015) e apenas cerca de $10 \%$ dos graduados universitários do Brasil possuem títulos em ciência ou engenharia (IRI, 2016). O cenário brasileiro da inovação será mais bem detalhado na seção seguinte deste trabalho.

\section{A Inovação na Indústria Brasileira}

Dado a análise da situação brasileira quando comparado com outros países do mundo, é preciso entender o perfil da Indústria Brasileira, que será realizada nessa seção com foco em quatro aspectos importantes: Perfil dos dispêndios das empresas; Políticas públicas e incentivos à inovação; e Cooperação universidadeempresa.

\subsection{Perfil dos dispêndios das empresas}

No Brasil, a política de inovação é acompanhada por meio da Pesquisa de Inovação (PINTEC), realizada pelo Instituto Brasileiro de Geografia e Estatística (IBGE). Nessa pesquisa foram mensurados, dentre muitos outros aspectos, os dispêndios das empresas inovadoras em atividades inovativas, conforme identificado 
no Gráfico 01 adiante. A PINTEC considera as indústrias por setores, sendo eles: Indústrias Extrativas; Indústrias de Transformação; Eletricidade e Gás; e Serviços.

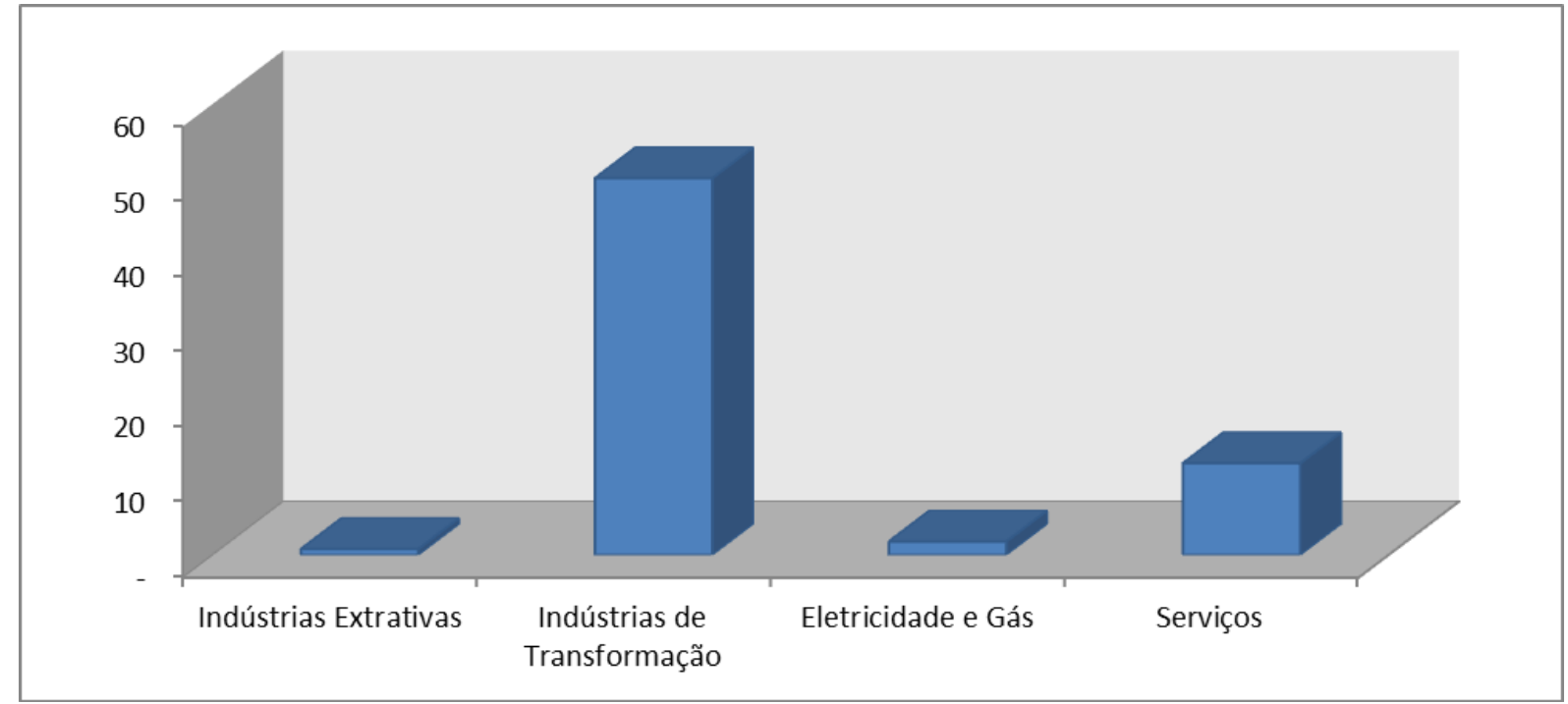

\section{Figura 1}

Dispêndio das empresas com atividades de inovação por tipo de indústria (em Bilhões de $\mathrm{R} \$$ )

Fonte: Adaptado de IBGE (2015).

Os gastos com inovação no Brasil, segundo dados do IBGE (2015), apresentam resultados que permitem identificar a relação de dispêndios da indústria com inovação. Como característica, a indústria de transformação apresenta-se com maior intensidade de dispêndios em inovação, pela própria característica da indústria, que se vê constantemente forçada a inovar para se manter competitiva no mercado. Além disso, são nessas indústrias que emergem a maior parte das inovações de produtos. As indústrias extrativas e Eletricidade \& Gás apresentam maior tendência à inovação de processos. A inovação de produto, segundo o manual de Oslo, é considerada como mudanças radicais ou incrementais em produtos e serviços. Nesse sentido, serviços também entram no hall das inovações em produtos, e a indústria de Serviços, segundo dados da IBGE (2015), é a segunda que mais apresentam dispêndios em atividades inovativas.

Quando considerados dados das empresas participantes da Lei do Bem (Melhor detalhada na seção 3.3), os dispêndios com atividades de inovação em relação ao PIB apresenta uma variação ao longo dos anos, havendo um ponto máximo em 2008 e reduções sucessivas até 2012. Nesse período, crises econômicas podem ter interferido nos investimentos em inovação. A despeito disso, 
os investimentos em P\&D por empresas não alcançaram 1\% do PIB, o que ainda reflete um investimento baixo em inovação. Esses dados são apresentados no Figura 2 e Tabela 3.

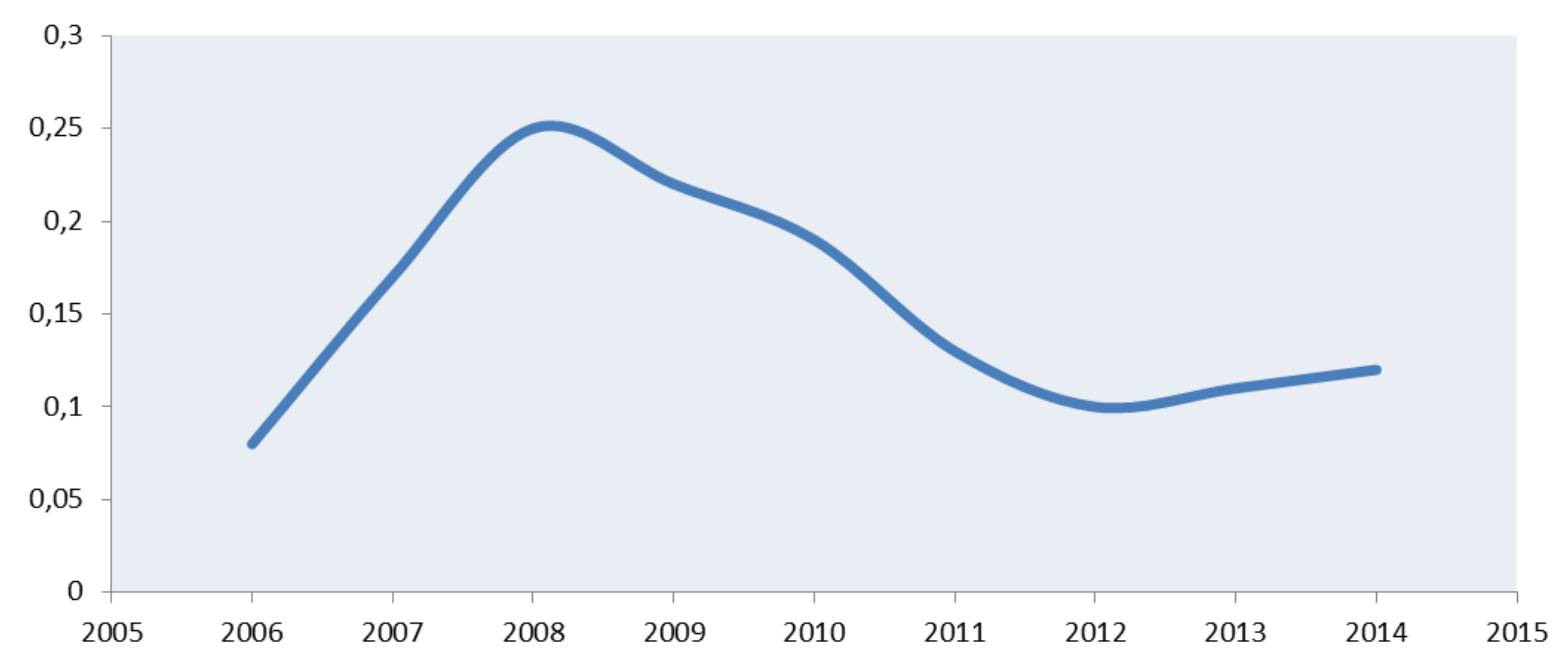

\section{Figura 2}

Investimentos das Empresas nas Áreas de P, D\&I em relação ao PIB do Brasil Fonte: Adaptado de (MCTI, 2014). Relatório Anual de Atividades de P\&D (Retificado), 2014

\section{Tabela 3}

Investimentos das Empresas em P\&D\&I em relação ao PIB do Brasil

\begin{tabular}{|c|c|c|c|c|c|c|}
\hline Ano-Base & $\begin{array}{c}\text { Investimento (A) } \\
(*)\end{array}$ & $\begin{array}{c}\text { Renúncia } \\
\text { Fiscal Total } \\
\text { (B) }\end{array}$ & $\begin{array}{c}\text { Investimento - } \\
\text { Renúncia Fiscal } \\
(\mathbf{A}-\mathbf{B})\end{array}$ & $\mathbf{P I B ( C )}(* *)$ & $\mathbf{( \% )}(\mathbf{A} / \mathbf{C})$ & (\%) ((A-B)/C) \\
\hline $\mathbf{2 0 0 6}$ & 2,19 & 0,23 & 1,96 & $2.433,00$ & 0,09 & 0,08 \\
\hline $\mathbf{2 0 0 7}$ & 5,14 & 0,88 & 4,26 & $2.558,80$ & 0,2 & 0,17 \\
\hline $\mathbf{2 0 0 8}$ & 8,8 & 1,58 & 7,22 & $2.889,70$ & 0,3 & 0,25 \\
\hline $\mathbf{2 0 0 9}$ & 8,33 & 1,38 & 6,95 & $3.143,00$ & 0,27 & 0,22 \\
\hline $\mathbf{2 0 1 0}$ & 8,62 & 1,73 & 6,89 & $3.675,00$ & 0,23 & 0,19 \\
\hline $\mathbf{2 0 1 1}$ & 6,84 & 1,41 & 5,43 & $4.143,00$ & 0,17 & 0,13 \\
\hline $\mathbf{2 0 1 2}$ & 5,34 & 1,05 & 4,29 & $4.403,00$ & 0,12 & 0,1 \\
\hline $\mathbf{2 0 1 3}$ & 6,74 & 1,59 & 5,15 & $4.840,00$ & 0,14 & 0,11 \\
\hline $\mathbf{2 0 1 4}$ & 8,19 & 1,71 & 6,48 & $5.521,00$ & 0,15 & 0,12 \\
\hline
\end{tabular}

Fonte: Adaptado de MCTI (2014). Relatório Anual de Atividades de P\&D (Retificado) 2014.

$\left({ }^{*}\right)$ Refere-se ao investimento recomendado para cálculo dos Incentivos Fiscais adicionais concedidos pela Lei do Bem. Valores revisados e corrigidos. $\left.{ }^{* *}\right)$ Refere-se aos dados do IBGE.

\subsection{Um panorama das empresas inovadoras industriais no Brasil}

Dados da PINTEC (IBGE, 2004), posteriormente analisados (De Negri, Salerno, \& Castro, 2005), fornecem uma noção sobre o perfil das empresas inovadora no Brasil, considerando uma amostra estatisticamente significativa de 
72.000 empresas industriais, no período de 1998 e 2004. Os dados levam aos seguintes resultados:

- Empresas que inovam em produtos e processos: $33,0 \%$ (31,5\% em 1998, $33 \%$ em 2001, 33\% em 2004);

- Setores que mais inovam: rápida incorporação em produtos/serviços/processos de conhecimentos técnico-científicos (informática, eletrônico, comunicações);

- Gasto em P\&D/faturamento: $3,8 \%$, mas $75 \%$ do total relacionado a compra de maquinas/equipamentos para fabricação, principalmente no âmbito das PMEs; Gasto real de 0,95\%;

- Pessoal em P\&D: 41.600 mil pessoas, 50\% TNS, 50\% em part-time $(0,25$ pessoa/empresa, em média).

Uma análise comparativa das empresas quanto a fatores específicos nas dimensões produto, mercado, processo e outros impactos, utilizando-se fatores como market share, produtividade, remuneração dos empregados, escolaridade dos empregados, turnover e impactos ao meio ambiente, assim como do nível de cooperação tecnológica por porte e setor industrial, nos permite chegar aos seguintes estratos ou clusters:
A - Firmas que inovam e diferenciam produtos
B - Firmas especializadas em produtos padronizados
C - Firmas que não diferenciam produtos e têm produtividade menor

O primeiro grupo é formado por 1.200 firmas (1,73\% do total de 72.000$)$, são de grande porte, exportam com valor 30\% maior que concorrentes do país importador. Tem como foco a inovação de produtos e intensidade de P\&D de cerca de 3,0 \% faturamento anual, um índice próximo a média da Alemanha, que é 2,7\%. O grupo B, por sua vez, formado por 15.300 firmas (20,3\% do total), é caracterizado por empresas de grande porte, que exportam, mas sem adicionar valor. Inovam mais em processos, alcançando escala, produtividade e baixo custo, ainda que inovam em produtos padronizados. A intensidade de P\&D média desse grupo é de 0,99\% do faturamento anual (média Brasil: 0,7 \%). Porem, 15\% das firmas desse grupo começam a inovar em produtos, o que significa que no futuro o grupo A pode 
aumentar". O grupo C, finalmente, é formado por 55.000 firmas (78 \% do total), tem baixa produtividade, não se diferenciam e pouco inovam. São muito pouco capacitadas tecnologicamente, constituindo-se num retrato típico do que acontece na maioria dos países retardatários.

Em síntese, comparativamente, as empresas do Grupo A, podem ser consideras inovadoras e capacitadas para o jogo global, contendo muitas daquelas que se conveniou chamar de Multilatinas, isto é, empresas brasileiras internacionalizadas. Comparativamente as dos demais grupos têm as seguintes características que as distinguem:

(1) Mais produtivas e maiores market share;

(2) Mais inovam e diferenciam produtos

(3) Maior intensidade de P\&D

(4) Utilizam mais a cooperação tecnológica (ex. universidades). A cooperação é maior nos setores de menor intensidade tecnológica (33,9\%), comparado aos setores de maior intensidade tecnológica (18,9\%)

(5) Faturamento médio anual: US $\$ 60$ milhões $\times 10$ milhões (B) e 0,6 milhões (C)

(6) Remuneração média do trabalho/mês: US $\$ 570,00 \times 340,00$ (B) e 195,00 (C)

(7) Escolaridade média: 9,13 anos x 7,64 (B) x 6,89 (C)

(8) Permanência no emprego: 54 meses $\times 43$ meses (B) $\times 35$ meses (C)

Portanto, pode-se concluir que a inovação traz redução de custos, melhoria na qualidade de produtos, ampliação ou manutenção de Market-share, possibilidade de abertura de novos mercados, impactos positivos ao meio ambiente, e melhor enquadramento nas normas comerciais dos mercados interno e externo. $O$ treinamento e escolaridade dos colaboradores técnicos aumentam a capacitação e, assim, a probabilidade de ser inovadora e exportar. A cooperação tecnológica, quando bem sucedida, permite soluções mais criativas que as realizadas pela empresa individualmente, a transferência de conhecimento entre os agentes envolvidos e a criação de vantagens competitivas para ambos, num jogo típico de ganha-ganha.

De fato, os investimentos em inovação na grande maioria das empresas do Brasil estão concentrados em processos (compra de máquinas) e não em produtos, que melhoram escala e produtividade, mas não levam a empresa necessariamente 
para o grupo A. Assim, recursos públicos, via incentivos direitos (financiamentos com ou sem retorno), embora importantes para inovação em processos, não o são, na mesma magnitude, para a inovação em produtos (Marcovitch, Sbragia, Stal, \& Terra, 1991). Estes dependem muito mais de investimentos privados, que podem ser estimulados por políticas públicas (mecanismos tributários) que minimizem risco e custo do investimento em P\&D (Terra \& Sbragia, 1994)

\subsection{Políticas públicas \& Incentivos para a Inovação}

As políticas públicas brasileiras com direcionamentos à inovação são relativamente novas, quando comparado com países mais desenvolvidos. O movimento mais forte para inovação aconteceu em 2004, com a criação da lei no 10.973 de 2004 (BRASIL, 2004), lei de inovação, regulamentada pelo decreto $n^{-}$ $5.563 / 2005$, que direcionou os esforços de regulamentação e criação de ambientes propícios para a inovação no Brasil. Essa lei, em 2016, foi alterada pelo novo marco legal da ciência e tecnologia, que a tornou mais dinâmica e permitiu aprimoramentos até então não resolvidos na lei de 2004. Desde lá, movimentos de incentivo à inovação ganharam força, inclusive com a aplicação de incentivos às empresas, estimulando, sobretudo, a relação de empresas com Instituições Científicas e Tecnológicas.

A lei, nessa direção, permitiu que o público e o privado conversassem com maior fluidez, em uma relação construtiva e que permitiu que conhecimentos e tecnologias desenvolvidas em universidades públicas ou Institutos de Pesquisas pudessem ser exploradas por empresas licenciadoras, levando resultados ao mercado e gerando faturamento.

Além disso, outras leis foram criadas no sentido de promover o desenvolvimento de inovações em empresas. Um exemplo é a Lei do Bem (11.196/2005), regulamentada pelo decreto № 5.798/2006, que estimula as empresas a investirem em atividades de inovação. Há, como contrapartida, o abatimento de parte das despesas com essas atividades dos impostos devidos, tudo regulamentado segundo normas específicas, e que permitiu com que as empresas se valessem desses estímulos para intensificar os seus dispêndios em atividades inovativas, criando e/ou aprimorando assim os seus produtos, serviços e processos. 
No ano base de 2014, 1.008 empresas valeram-se dos benefícios da Lei do Bem frente a 1.206 empresas participantes. A evolução desses números demonstra uma intensificação na participação das empresas como usufruidoras da Lei, denotando um aumento na busca por inovação por parte das empresas. O Gráfico 03 apresenta o histórico das empresas participantes vs. recomendadas, com base nos registros apresentados no Relatório Anual da Lei para o ano base 2014, o mais recente disponibilizado.

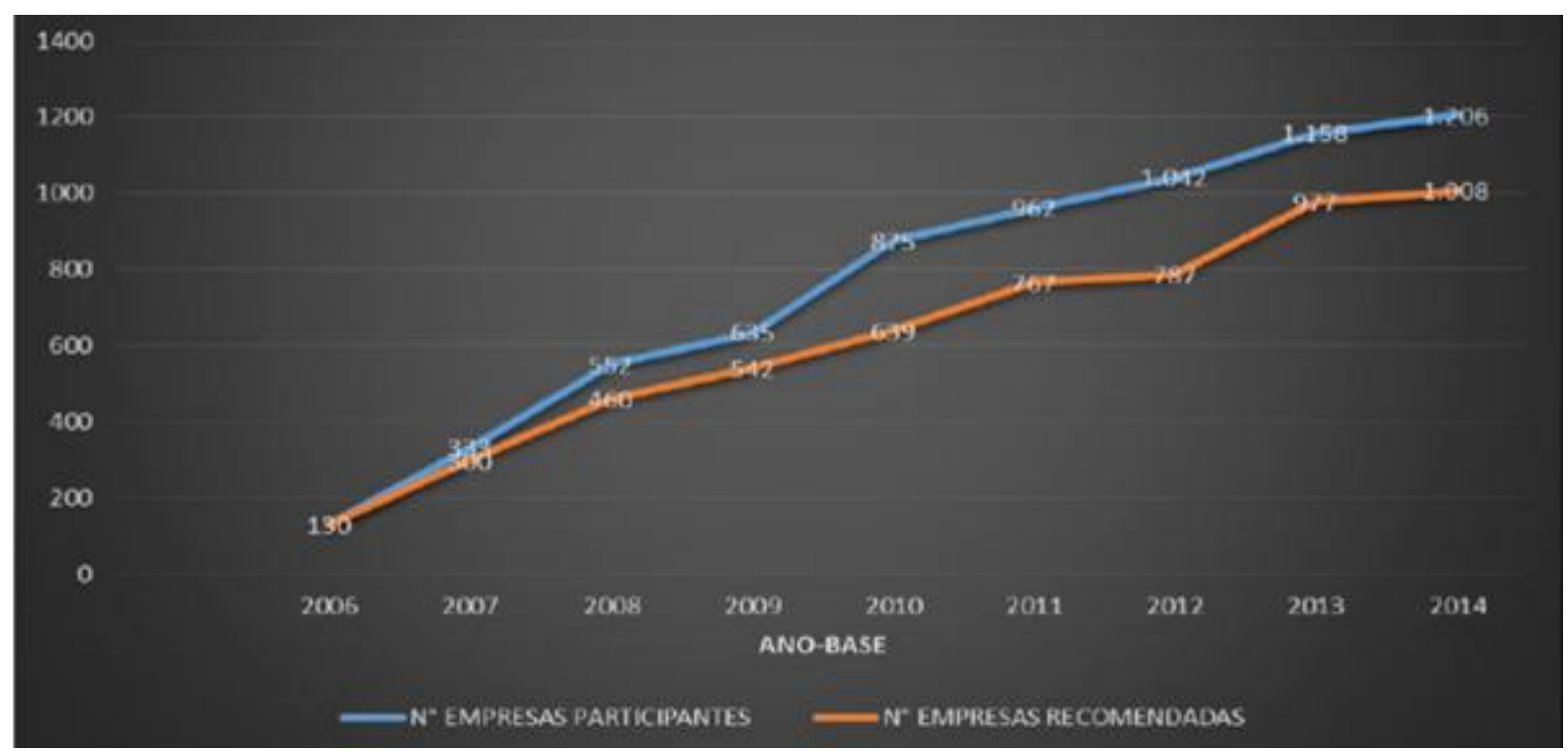

\section{Figura 3}

Histórico das empresas Participantes vs. Recomendadas na Lei do Bem (Ano base 2014)

Fonte MCTI (2014, p. 13). Relatório Anual de Atividades de P\&D (Retificado) 2014

Quando se analisa por setores, percebe-se que os setores de Mecânica e Transporte, Software, Petroquímica / Química, Eletroeletrônica e Alimentos são os mais representativos em termos de número de empresas participantes, conforme apresentado no Tabela 4 . 


\section{Tabela 4}

Empresas participantes da Lei do Bem por Setor

\begin{tabular}{|l|c|c|c|}
\hline \multirow{2}{*}{\multicolumn{1}{c|}{ SETORES }} & \multicolumn{3}{c|}{ EMPRESAS PARTICIPANTES } \\
\cline { 2 - 4 } & Declaradas & $\begin{array}{c}\text { Recomendadas } \\
\left({ }^{*}\right)\end{array}$ & $\begin{array}{c}\text { Não } \\
\text { Recomendadas } \\
\left({ }^{* *}\right)\end{array}$ \\
\hline Mecânica e Transporte & 200 & 190 & 10 \\
\hline Software & 173 & 145 & 28 \\
\hline Petroquímica / Química & 99 & 81 & 18 \\
\hline Eletroeletrônica & 91 & 86 & 5 \\
\hline Alimentos & 87 & 74 & 13 \\
\hline Bens de Consumo & 66 & 43 & 23 \\
\hline Farmacêutica & 48 & 44 & 4 \\
\hline Metalurgia & 47 & 39 & 8 \\
\hline Moveleira & 22 & 5 & 17 \\
\hline Mineração & 20 & 17 & 3 \\
\hline Papel e Celulose & 22 & 19 & 3 \\
\hline Têxtil & 14 & 5 & 9 \\
\hline Construção Civil & 22 & 18 & 4 \\
\hline Agroindústria & 16 & 15 & 1 \\
\hline Telecomunicações & 13 & 12 & 1 \\
\hline Outras & 266 & 215 & 51 \\
\hline TOTAL & 1.206 & 1.008 & 198 \\
\hline
\end{tabular}

Fonte: MCTI (2014, p. 14). Relatório Anual de Atividades de P\&D (Retificado) 2014.

Por regiões, os dados mostram que a maior intensidade de empresas declaradas na Lei do Bem se concentra no Sudeste e Sul, respectivamente. Nas demais regiões - Nordeste, Norte e Centro-Oeste - o volume de empresas participantes ainda é muito baixo, porém, apresentou uma evolução em termos absolutos, que também refletiu a importância da lei para o fomento à inovação nessas regiões, conforme mostra o Figura 4. 


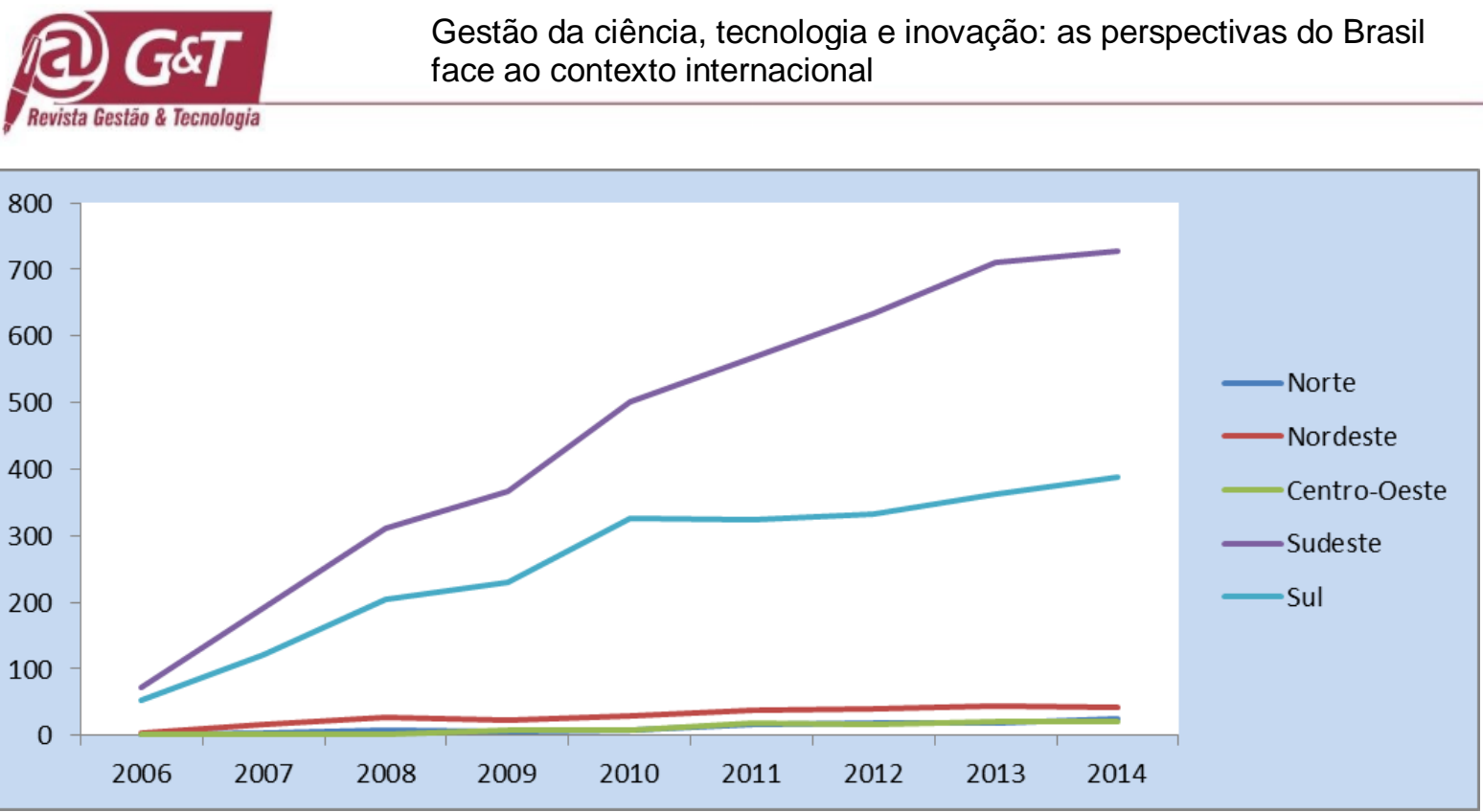

Figura 04

Empresas declaradas $x$ ano base

Fonte Adaptado de MCTI (2014). Relatório Anual de Atividades de P\&D (Retificado) 2014.

Apesar dos números apresentarem evolução no número de empresas participantes e declaradas, Fabiani \& Sbragia (2014) afirmam que o numero de empresas usuárias da Lei do Bem ainda é muito pequena, e apontam, principalmente, duas razões para isso: (1) Apenas empresas com regime de tributação sobre o lucro real e com a obrigação de determinação do lucro tributável no ano base em questão são consideradas, e (2) A incerteza jurídica e a falta de conhecimento sobre a legislação por parte dos empresários brasileiros.

\subsection{Cooperação universidade-empresa}

A inovação se inicia com atividades de Pesquisa. Porém, essas atividades mostram-se caras para a empresa, que muitas vezes não possuem competências necessárias e suficientes para desenvolver uma tecnologia a partir de estágios iniciais. Para isso, muitas empresas, a fim de reduzir o custo do processo de Pesquisa e Desenvolvimento, optam por firmarem cooperações com universidades, explorando assim uma vantagem apresentada pelas universidades, a de possuírem linhas de pesquisas já bem definidas, com grupos de pesquisas atuantes principalmente na etapa de pesquisa básica e aplicada.

Dessa forma, as universidades desenvolvem as tecnologias e as empresas as licenciam como forma de explorá-las após escaloná-las. Essa cooperação pode acontecer de algumas formas, dentre elas, cita-se mais comumente a parceria de desenvolvimento conjunto e o licenciamento. Por meio da parceria de 
desenvolvimento conjunto, as empresas buscam a universidade e, juntos, desenvolvem uma tecnologia necessária à empresa. Nesse formato, pesquisadores da universidade e pesquisadores/funcionários das empresas se envolvem em uma mesma pesquisa, patrocinada pela empresa e conduzida de forma conjunta, dentro de parâmetros legais necessários e exigidos de acordo com a política de inovação da Instituição de Ciência e Tecnologia e com o aval da empresa.

Diante disso, entende-se que a cooperação universidade-empresa acontece segundo alguns passos, que são apresentados por (Sbragia, 1994) como iniciando na Disposição de Cooperar. As partes somente iniciarão o processo de cooperação se estiverem dispostas e inclinarem-se a tal, motivadas em boa parte (i) pelo interesse da empresa de complementar suas competências com conhecimentos disponíveis nas universidades por meio dos seus pesquisadores, e (ii) pela universidade que se interessa, pela oportunidade e pelo apoio financeiro da empresa no sentido de desenvolver suas pesquisas e equipar seus laboratórios.

Essa disposição levará à uma etapa próxima, que é refletida na Negociação e Comprometimento, quando as partes começam, de maneira mais prática, formular o escopo da cooperação e da interação entre elas, definindo os limites e aspectos necessários para a condução da interação. Com isso em mãos, passa-se à execução propriamente dita, que contempla a condução conjunta das atividades e, nesse ponto, seguem-se as etapas previstas no projeto. Ao final, os resultados dessa cooperação emergirão e a qualidade desses resultados influenciarão disposições de cooperações futuras entre universidades e empresas. A Figura 1 apresenta a ideia desse ciclo: 


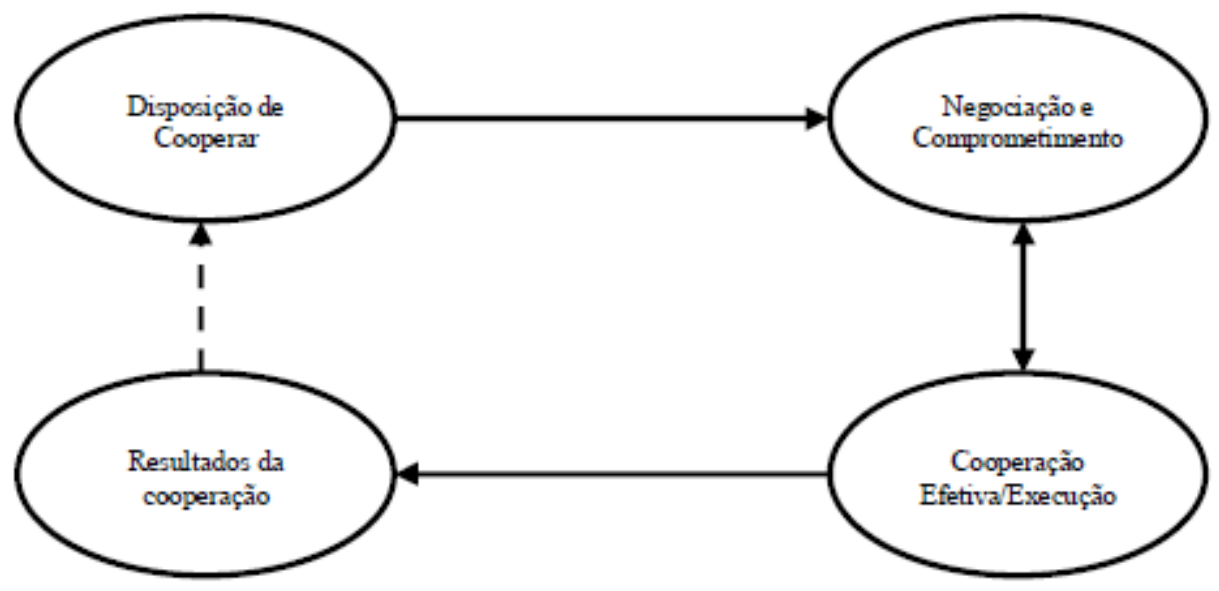

\section{Figura 5}

Ciclo de Cooperação Universidade-Empresa

Fonte: elaborada pelos autores.

Há vários fatores que levam as universidades e empresas a integrarem um processo de cooperação. Para a universidade, a cooperação com empresas permite a obtenção de recursos para pesquisas e a envolve em um contexto de discussões práticas que refletem as necessidades das empresas no mercado, mantendo-a próxima da dinâmica da indústria e estudando assuntos a ela relacionados. Atualiza assim seus conhecimentos, diminuindo o gap entre o que faz e as necessidades das empresas. Do ponto de vista de aspectos mais tangíveis, essas relações permitem que as universidades insiram seus estudantes em oportunidades de primeiro emprego em empresas consolidadas no mercado. Além disso, há também possibilidades de firmarem contratos de consultorias para pesquisadores, que atualmente é regulamentado e contribui para reduzir a distância na relação públicoprivado que tem que se apresentar cada vez mais próximas para que um bom sistema nacional de inovação funcione e gere resultados de sucesso.

Da parte da empresa, a cooperação também é motivada por alguns fatores, distintos da universidade, porém, igualmente importantes. Com cooperação com a universidade, a empresa garante acesso a recursos humanos qualificados, muitas vezes a um custo mais baixo do que construir uma estrutura dentro da organização, contratando recursos humanos de igual qualificação por conta própria. Além disso, a empresa consegue, por meio da proximidade com conhecimentos desenvolvidos nas universidades, compreender os avanços das suas áreas de atuação, podendo rapidamente proceder a reorientações de conduta caso caminhe em terrenos 
sinuosos. Acesso a resultados de pesquisa antes mesmo que outras empresas o acessem também é um dos fatores que levam à cooperação, muitas vezes esses resultados levam a soluções de problemas específicos, viabilizados por meio da utilização de laboratórios e instalações. Outros aspectos que levam à cooperação universidade-empresa são refletidos na formação dos funcionários, melhoria da imagem e prestígio dentro da sociedade, necessidade de aumentar sua competitividade - muitas vezes por meio de inovações que são geradas a partir dessa interação. Em muitos casos, ainda, a cooperação com universidades compõe a estratégia tecnológica da empresa, o que a permite elevar o padrão de competição em seu setor. E dentre esses, talvez o fator que mais atrai as empresas à cooperação é a possibilidade de redução de custo e risco frutos dessas relações. A Tabela 5 sintetiza esses fatores.

\section{Tabela 05}

Fatores que levam à cooperação Universidade-Empresa

\begin{tabular}{|c|c|}
\hline UNIVERSIDADE & EMPRESA \\
\hline $\begin{array}{l}\text { Obtençào de novos recursos para pesquisa } \\
\text { Aumento da relevância da pesqui sa académica ao } \\
\text { lidar com necessidades dai indústria ou da sociedade, e } \\
\text { o consequente impacto no ensino; } \\
\text { Possibilidade de emprego para estudantes graduados; } \\
\text { Possibilidade de futuros contratos de consultoria para } \\
\text { pesqui sadores } \\
\text { Possibilidade de futuros contratos de pesquisa }\end{array}$ & 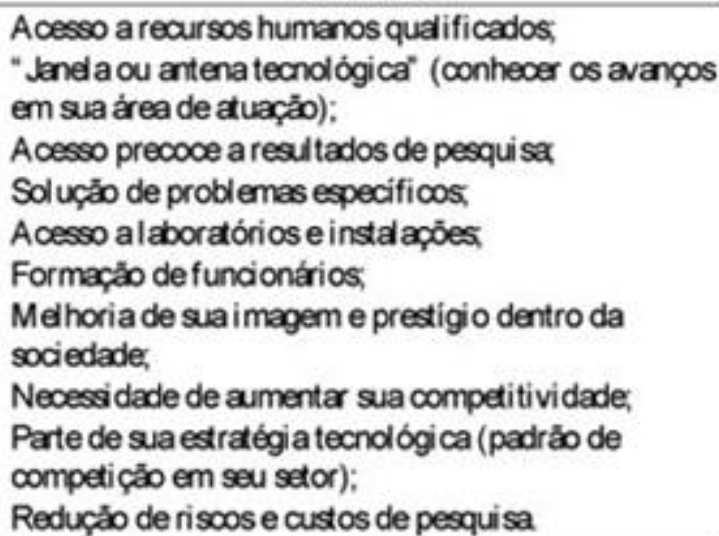 \\
\hline
\end{tabular}

Fonte: Sbragia (1994); Segatto (1996)

As barreiras à cooperação também são evidenciadas e levantadas na literatura. Para a universidade, por exemplo, há uma incompatibilidade entre as regras existentes e as necessidades das empresas. As regras muitas vezes engessam as universidades, tornando seus processos morosos e incompatíveis com a necessidade de redução do lead time nas empresas. O Tabela 6 sintetiza essa relação. 
Tabela 06

Barreiras à cooperação Universidade-Empresa

\begin{tabular}{|c|c|}
\hline UNIVERSIDADE & EMPRESA \\
\hline $\begin{array}{l}\text { Falta de regul amentaçōes ou excessiva rigidez das } \\
\text { existentes }\end{array}$ & $\begin{array}{l}\text { Escasso reconhecimento da tecnologia nos planos } \\
\text { empresarias. }\end{array}$ \\
\hline $\begin{array}{l}\text { Náo utilização de politicas mercadológicas aplicáveis } \\
\text { à oferta tecnológica uni versitária }\end{array}$ & $\begin{array}{l}\text { Preferência por licenciar tecnologia ao invés de } \\
\text { desenvol vêla. }\end{array}$ \\
\hline $\begin{array}{l}\text { Descontinuidade de projetos em decorrência de } \\
\text { problemas pol iticos écu trabal histas }\end{array}$ & $\begin{array}{l}\text { Visáo imediatista dos negódios, que năo indui a } \\
\text { pesquisa, }\end{array}$ \\
\hline $\begin{array}{l}\text { Docentes nấ preparados para a realizaçăo de projetos } \\
\text { de P\&D e com formaçấo unidisciplina; }\end{array}$ & $\begin{array}{l}\text { Exigéncia de segredo e propriedade dos resul tados da } \\
\text { pesquisa }\end{array}$ \\
\hline $\begin{array}{l}\text { Pesquisadores isol ados da redidade, sem compreender } \\
\text { as necessidades do setor produtivo; } \\
\text { Maior valorizaçăb da pesqui sa básica do que da }\end{array}$ & $\begin{array}{l}\text { A mbientes e estruturas organizacionais inadequadas para } \\
\text { a vincul açăb, além da faita de recursos financeiros para } \\
\text { financiar projetos; }\end{array}$ \\
\hline pesqui sa tecnológica aplicada e sua comercializaçăo, & Pessod desatualizado e com baixa motivaçäo; \\
\hline $\begin{array}{l}\text { Diferenças culturais, de valores, atitudes e formas de } \\
\text { trabalho, dificultando a comunicaçăo, além de }\end{array}$ & $\begin{array}{l}\text { Desconhecimento da capacitaçăo universitária } \\
\text { A verş̄o ao risco; }\end{array}$ \\
\hline diferentes concepcōes do tempo; & Baixo compromisso com a participaçäo nos projetos: \\
\hline $\begin{array}{l}\text { Visăo do setor produtivo como somente interessado } \\
\text { em seus benef icios próprios e nấ em retribuir à } \\
\text { universidade e à sociedade, }\end{array}$ & 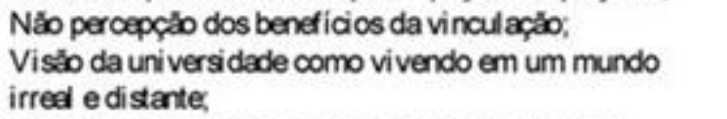 \\
\hline $\begin{array}{l}\text { Lentidåo nos trâmites burocrấticos para aprovaçẳo de } \\
\text { convênios }\end{array}$ & $\begin{array}{l}\text { Suspeita e desconfiança nas capacidades dae nos } \\
\text { resultados de suas atividades. }\end{array}$ \\
\hline Faita de recursos financeiros & Sentimento de inferioridade com relachab aos \\
\hline Carga horária elevada dos professores. & $\begin{array}{l}\text { conhecimentos existentes na universidade, } \\
\text { Imediatismo da indústria'empresa na busca por } \\
\text { resultados. }\end{array}$ \\
\hline
\end{tabular}

Fonte: Adaptado de (Garnica, Ferreira Junior, \& Fonseca, 2005; Mancini \& Lorenzo, 2006)

Em linhas gerais, há uma conhecida dificuldade na relação entre universidades e empresas, sendo refletida, primordialmente, na diferença cultural desses dois setores. A universidade, por um lado, apresenta uma rigidez maior nas suas regulamentações, e seus pesquisadores, não obstante essa rigidez, interessam-se, mormente, pela publicação de suas pesquisas em revistas especializadas, ao invés de proteger esse conhecimento. Além disso, pesa a morosidade nas tramitações dos processos, que torna o tempo de transferência incompatível com as necessidades das empresas. Os recursos, ainda assim, mostram-se escassos e seus pesquisadores, muitas das vezes, apresentam uma carga horária de dedicação à universidade que os impedem de dedicarem com intensidade maior às pesquisas desenvolvidas conjuntamente com as empresas.

Por outro lado, as empresas buscam desenvolvimento e lançamento rápido de tecnologias para tirar vantagens antes que outro concorrente as copie, o que reflete a vantagem de serem first movers. Isso muitas vezes faz com que a empresa apresente uma concepção equivocada do tempo necessário para o desenvolvimento 
de uma pesquisa, deixando que os interesses e impulsos de mercado atropelem os passos necessários e suficientes para uma boa condução dos projetos.

\section{A Gestão da Inovação sob a perspectiva da Empresa}

As empresas envolvidas em ambientes cada vez mais complexos necessitam enfrentar e superar muitas restrições para se manterem competitivas num mercado global. As restrições devem ser vistas, de fato, como fatores estimulantes da inovação, obrigando as empresas a mobilizarem seus recursos, competências e estruturas em direção a resultados que agreguem valor.

De fato, no contexto atual, as empresas tem que obter alta performance sob condições muito complexas, particularmente aquelas dos mercados emergentes, onde predominam:

- Tecnologias nem sempre acessíveis e a falta de conhecimento técnico que facilite a assimilação de novas, bem como o aprendizado de experiências externas, quer no âmbito das próprias empresas, como do das universidades e institutos de pesquisa;

- Recursos humanos não disponíveis e que não contam as competências requeridas e nem estão envolvidos em constante treinamento e educação na área técnica.

- Crença geral de que as novas tecnologias e os processos de inovação são caros e que representam um custo, não um investimento;

- Pouca assimilação de ferramentas para antever a evolução das tecnologias envolvidas nos negócios chave das empresas e suas possíveis evoluções;

- Uma perspectiva parcial do lado gerencial da Inovação Tecnológica, que produz uma sensação de um processo caótico e incontrolável;

- Restrições financeiras, sem sempre criativamente tratadas como parte inerente ao processo de inovação, que é de risco.

\subsection{A cadeia necessidade-resposta: da inovação para a capacitação}

Como dito, as empresas vivem atualmente num contexto nacional e internacional que apresentam altos requisitos de competitividade. Para tal, 
necessitam continuamente inovar, em áreas fins, em produtos e serviços, e, em áreas meio, em processos, sistemas e procedimentos. Para viabilizar tais conquistas necessitam de capacitação tecnológica. Mas qual o significado de inovação e como a mesma agrega valor? Do ponto de vista econômico-financeiro (Business Performance), a empresa visa a maximização dos resultados para os acionistas, isso inclui cumprir metas e indicadores como crescimento de vendas, participação no mercado, lucratividade, rentabilidade, etc. Contudo, para se chegar a isso, na era atual da competição, é necessário para empresa inovar, cumprindo resultados inovadores (innovative performance), tanto fins, como novos produtos e serviços, que agregam valor provenientes do mercado, como meios (processos e procedimentos), que agregam valor relacionados a índices de eficiência, produtividade, etc. É o que denomina atualmente de Value Innovation (Sbragia \& Boscolo, 2011). A Figura 6 representa resumidamente essa noção.

\section{CRITÉRIOS DE DESEMPENHO EMPRESARIAL}

\section{INNOVATIVE PERFORMANCE (meio)}

1. \% Novos produtos no faturamento

2. Redução do "Lead Time" (tempo entre o Desenv e a Comerc.)

3. Redução do índice de defeitos (qualidade)

4. Venda de tecnologia para terceiros (patentes)

\section{BUSINESS PERFORMANCE (fim)}

1. Crescimento de vendas

2. Participação no mercado (Market Share)

3. Lucros ou lucratividade (Lucro/Faturamento)

4. Rentabilidade (Lucro/Patrimônio Líquido)

5. Valor para os acionistas (Valor Criado)

\section{Figura 6}

A inovação de valor

Fonte: Adaptado de Sbragia, R., \& Boscolo, R. (2011). Estratégia, Inovação e Desempenho: Uma análise da relevância da inovação de valor no desempenho das empresas. Revista Espacios, 32(1), 35 .

Quanto à capacitação tecnológica, ela pode ser conquistada de diferentes maneiras, como mostra a Figura 3. Num estágio preliminar, as empresas se capacitam através de mecanismos informais internos, como invenção e conhecimento intuitivo, derivados de soluções buscadas a partir de conhecimentos 
tácitos, acumulados mediante um processo de aprendizagem, quer no âmbito da Manufatura como do Controle de Qualidade, Assistência Técnica, pós-vendas, etc.

Num segundo plano, podem se valer de recursos externos, ainda que de forma, intuitiva, se valendo de alternativas como imitar, consultar experts externos, fazer busca em bancos de patentes, etc. Num terceiro, já de uma maneira mais formal, podem se valer de práticas mais formalizadas, como contratar pessoal especializado segundo perfis desejados, adquirir pacotes tecnológicos, realizar parcerias, etc. Num plano mais completo, podem praticar formalmente as atividades de P\&D, através de núcleos formalmente instituídos, que passam a ter uma responsabilidade formal pelo desenrolar dessa atividades, quer centralizada (Corporate $R \& D$ ), descentralizadamente (Núcleos de P\&D dispersos ao longo de áreas de negócios ou filiais) ou de forma combinada (Vasconcellos, 1979).

Internos (Fazer)

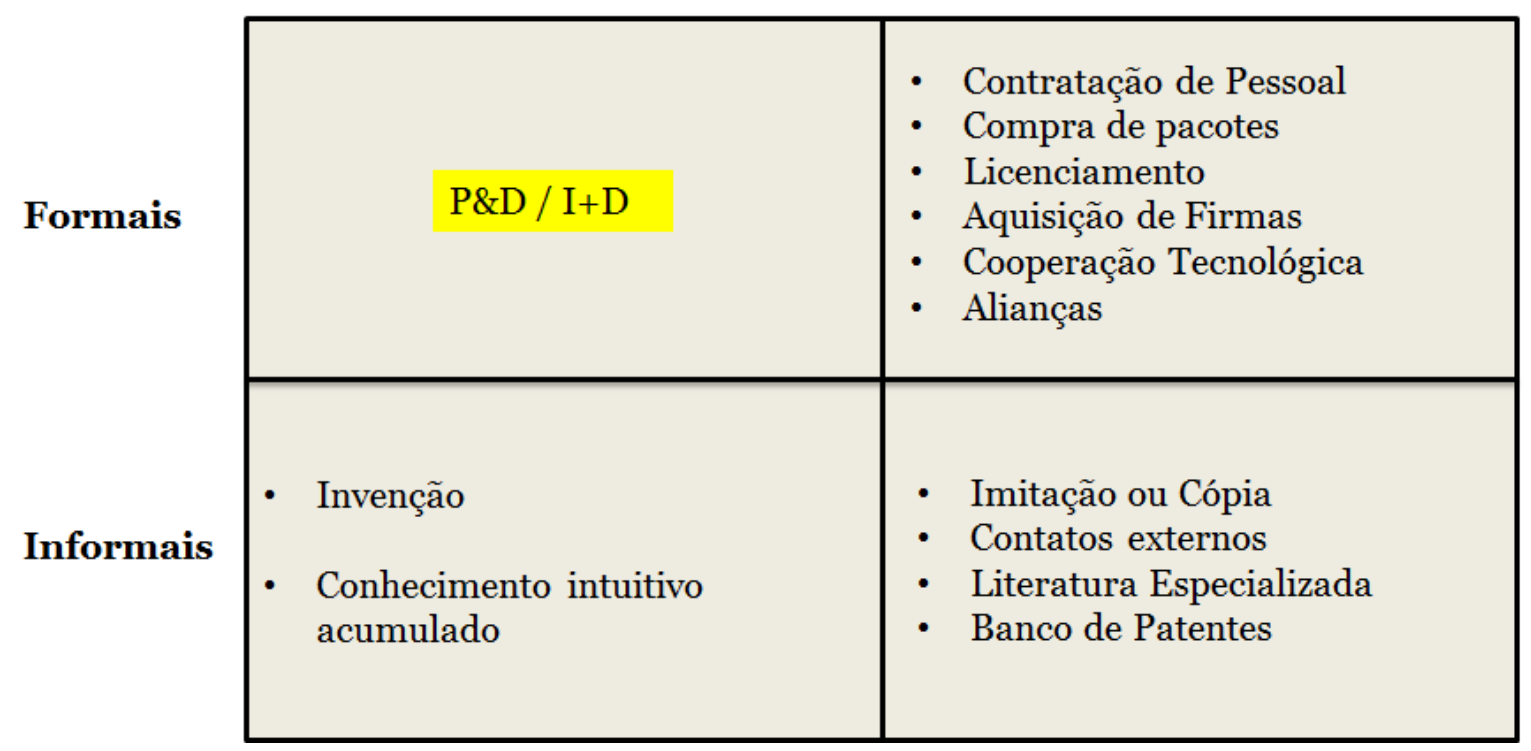

Figura 7

Mecanismos para Capacitação Tecnológica na Empresa

Assim, numa evolução gradativa, que ocorre muitas vezes de maneira não planejada, a empresa passa de uma abordagem de Embeded R\&D para uma de Explicit $R \& D$. Num limite, a primeira alternativa corresponderia ao que se pode chamar de P\&D residual, ou seja, eliminando-se todos os aparatos formais da organização, restariam conhecimentos, práticas e procedimento que estariam embutidos nas pessoas e em suas condutas individuais. 
Mas o que significa P\&D? O que estaria fazendo uma empresa quando pratica P\&D. Num conceito restrito, conforme definido pelo Manual Frascati (OCDE, 1973), estaria executando atividades de pesquisa básica e aplicada, além do desenvolvimento experimental. Contudo, no domínio das empresas não se pratica decididamente Pesquisa Básica, talvez algo de Pesquisa Aplicada, mas notadamente Desenvolvimento. Para caracterizar melhor o que se faz de P\&D numa empresa típica, o Manual de Oslo (OECD, 1997) propõe um alargamento desse conceito, valido para o setor empresarial, incluído os serviços tecnológicos, a engenharia não rotineira, a produção do lote experimental e mesmo os testes de mercado. Tal conceito alargado de P\&D, conhecido hoje pelo acrônimo P\&D\&I melhor caracteriza os espaço ocupado pelas atividades de pesquisa, desenvolvimento e inovação no meio empresarial. Tanto é verdadeiro que nos países mais desenvolvidos as práticas de incentivo fiscal à inovação privilegiam esse conjunto de atividades e não apenas as tradicionalmente conhecidas (P\&D) como objeto de aplicação de práticas reducionistas de custos para as empresas.

Estudos realizados a partir da base de dados da ANPEI- Associação Nacional de P\&D das empresas Inovadoras (Sbragia, Kruglianskas \& Arango-Alzate, 2001) mostraram, de forma sintética, que:

- O número de empresas inovadoras no Brasil ainda é proporcionalmente pequeno e se revela ainda muito menor quando se trata de empresas não só inovadoras, mas também tecnologicamente capacitadas.

- As empresas de menor porte são as mais inovadoras, ainda que o índice de projetos finalizados seja menor, provavelmente devido ao fator risco.

- As empresas que se apresentaram como inovadoras e capacitadas também se revelaram economicamente mais eficientes em termos de \% do lucro líquido/faturamento

- Coerentemente com a lógica, o estudo mostrou que as empresas que investem mais em P\&D\&I relativamente ao seu faturamento são as empresas que se mostram mais inovadoras

- Um aspecto pouco tratado na literatura, mas ressaltado no estudo é que as empresas mais inovadoras destinam prioritariamente seus dispêndios para manutenção de pessoal para P\&D\&E enquanto que as menos inovadoras 
destinam seus recursos de forma muito mais intensa para imobilizações de bens de capital para inovação e aquisições de tecnologia externa

\section{Conclusões e perspectivas}

Este artigo tratou de alguns números e perspectiva da C\&T\&I no Brasil a partir de uma análise retrospectiva e centrada nas empresas. Inicialmente desenhou-se um quadro do Brasil comparativamente ao mundo e à América Latina, particularmente. Depois tratou-se da inovação no Brasil e, mais especificadamente, da indústria brasileira e de suas características enquanto força tecnológica/Inovadora num país de enormes contrastes. Finalmente tratou-se da inovação de base tecnológica sob a perspectiva da empresa, notadamente das situadas no Brasil.

A título de síntese e conclusões, pode-se dizer que o Brasil é a 14a. economia e um entre os 10 maiores parques industriais do mundo, mas somente a 51a. nação competitiva (IMD). Em termos de IDH está além da 100․ posição. As empresas brasileiras tem dificuldade para acompanhar os padrões de consumo e as tendências tecnológicas mundiais, apresentando taxas de inovação muito baixas. De fato, deve-se considerar que as empresas não inovam sozinhas, mas dependem de um SNI efetivo. O do Brasil, porém, revela deficiências institucionais em quase todos seus agentes e dimensões.

Além do engajamento com a inovação ser, de um modo geral, culturalmente baixo por parte das empresas brasileiras, a articulação das mesmas com a infraestrutura científico-tecnológica é deficiente e as políticas governamentais orientadas a inovação são pobres e excessivamente burocratizadas.

De fato, a nível mundial, podemos resumidamente considerar 3 grandes classes de países, certamente com algumas imprecisões:

- Maduros: EUA, Alemanha, Japão, França, Reino Unido, Itália, etc.: contam com excelentes sistemas de C\&T e o transformam muito bem em inovação. São de fato Sistemas de C\&T\&l; 
- Intermediários: Suécia, Dinamarca, Holanda, Coreia, Taiwan, etc.: contam com bons-excelentes sistemas de $C \& T$, porém não conseguem uma transformação perfeita em inovação;

-Atrasados ou emergentes: Brasil e quase todos os países da América Latina: contam com sistemas fracos-razoáveis-bons de C\&T, porém, não conseguem transformá-los em sistemas efetivos de inovação, devido às graves deficiências em alguns aspectos, principalmente na articulação entre seus componentes (Empresas, Universidades e Governo), com falta de priorização às primeiras.

Por que um país que é um dos maiores na economia mundial, com a maior e mais diversificada indústria da América Latina, com uma infraestrutura científico/tecnológica respeitável e com um grande número de cientista e engenheiros, não consegue ser uma potência tecnológica? A resposta passa obrigatoriamente pela necessidade de as empresas buscarem uma competência internacionalizada, via, cumulativamente, ganhos de eficiência, qualidade, flexibilidade e, mais recentemente, INOVAÇÃO. Para tal, serão necessárias diretrizes e ações em várias dimensões capazes de viabilizar tais conquistas, sintetizadas e agrupadas neste trabalho em torno (Sbragia e outros, 2005):

(1) da Gestão Empresarial orientada para a Inovação,

(2) da Articulação Empresarial com o Sistema Acadêmico-Cientifico, e

(3) das Políticas Governamentais promotoras da inovação empresarial.

Do lado da gestao empresarial, a atividade inovadora deve estar completamente alinhada ao planejamento estratégico da organização, indo ao encontro de seus objetivos e interesses. Gastos em P\&D induzem novos produtos introduzidos no mercado, principalmente se a empresa atua em setores bastante dinâmicos. A P\&D próxima ao negócio e usando de esquemas organizacionais flexíveis pode aumentar a eficácia na transferência do conhecimento (da invenção para a inovação), dadas as caracteristicas compartimentadas encontrada na realidade das empresas. A empresa deve incentivar o intra-empreendedorismo entre seus funcionários, fazendo com que o germe da inovação seja inoculado em diferentes esferas. 
Por sua vez, para um resultado mais eficaz, a empresa deve tanto comprar tecnologia quanto manter uma equipe para desenvolvimento interno. Uma alternativa são os arranjos cooperativos para inovação, seja com outras empresas, institutos de pesquisa ou organização em redes. Variadas fontes de inovação, tanto internas quanto externas, envolvendo clientes, fornecedores, universidades e institutos de pesquisa, devem ser utilizadas. A eficácia de uma atividade de P\&D irá depender da contribuição dos diversos atores envolvidos.

Como forma de limitar a perda da memória corporativa, como resultado da variação de práticas gerenciais e intercâmbio de pessoas, a gestão do conhecimento é fundamental para evitar a repetição de erros, reduzir a duplicação de esforços e o tempo para a resolução de problemas.

Do lado da Articulação com a Infraestrutura Científico-Tecnológica, é necessário compreender as diferenças e gerenciar esta interface, para que as empresas não esperem algo que as universidades não podem oferecer - soluções prontas. Planejar uma cooperação sistemática e eficaz, começando de forma simples, como uma assessoria ou a realização de testes e ensaios, e progredir até arranjos mais complexos é a solução.

Por seu lado, universidades e institutos devem definir políticas claras de proteção à propriedade intelectual e critérios para licenciamento e comercialização. Mas antes, é preciso rever a cultura organizacional referente à parceria empresarial. Universidades devem criar ETT's com equipe especializada em identificação de oportunidades, seleção, negociação, comercialização e etapas finais da transferência, como já acontece hoje nas excelentes universidades do país. .

Do lado das políticas públicas, é necessário evoluir na eliminação das barreiras técnicas, na promoção de exportações com maior valor adicionado, e na maior proteção ao consumidor. Reforçar os sistema de propriedade intelectual e industrial, dando mais atenção para os movimentos de proteção utilizados pelos países centrais parece ser um caminho igualmente importante, além de desburocratizar o sistema de incentivos fiscais à inovação, tornando as ações dos agentes mais automáticas e focadas em segmentos de real demanda por apoio, particularmente as empresas de base tecnológica e as empresas com potencial exportador. Adicionalmente, deve-se criar e/ou fortalecer os incentivos financeiros 
em setores estratégicos, integrando o poder de compra de empresas estatais com ações dos bancos oficiais para obtenção de crédito e formação de capital de risco em atividades de intensa. Finalmente, é preciso também um esforço intenso de mobilização das Federações de Indústrias, Associações de Classe, e outras entidades representativas das empresas para a importancia e o papel da tecnologia/inovação na competitividade atual e futura das empresas.

Finalizando, mesmo tendo a participação do segmento produtivo nos DNCT's - Dispêndios Nacionais de Ciência e Tecnologia evoluído ao longo dos últimos 40 anos, de cerca de $5 \%$ para $40 \%$ em 2003 e para cerca de $60 \%$ na atualidade, as empresas que hoje investem em P\&D respondem por cerca de 1/3 do PIB Industrial Brasileiro, o que evidencia possibilidades de expansão futura, caso grandes crises não voltem a ocorrer e condições favoráveis sejam asseguradas. Mesmo porque INOVACAO É A PALAVRA DO MOMENTO NA ERA DA COMPETITIVIDADE GLOBAL.

\section{Referências}

Albuquerque, E. da M. e. (1996). Sistema nacional de inovação no Brasil: uma análise introdutória a partir de dados disponíveis sobre a ciência e a tecnologia. Revista de Economia Política.

Banco Central de Chile. (2017). Investigación. Retrieved November 5, 2017, from http://www.bcentral.cl/es/faces/home;jsessionid=8Ea9VJdtl-dGbrB8UjytwNvusKWRPIz5RmdHTp8xCJxpq4wpFn-!-166085304!1366034935?_afrLoop $=257524495036049 \&$ afrWindowMode $=0$ \&_afrWindowld =null\#!\%40\%40\%3F_afrWindowld\%3Dnull\%26_afrLoop\%3D257524495036049 \%26_afrWindow

Banco de México. (2007). Divulgación. Retrieved November 4, 2017, from http://www.banxico.org.mx/divulgacion/index.html

BRASIL. Lei n ${ }^{\circ}$ 10.973, de 2 de dezembro de 2004 (2004). Brasília. Retrieved from http://www.planalto.gov.br/ccivil_03/_ato2004-2006/2004/lei//10.973.htm

Carvalho, S. A., \& Furtado, A. T. (2017). A problemática dos indicadores de inovação na América Latina, pp. 1-5.

Cavalcante, L. R., \& De Negri, F. (2011). Trajetória recente dos indicadores de inovação no Brasil.

Cornell University, INSEAD, \& WIPO. (2017). The Global Innovation Index 2017: Innovation Feeding the World. Fontainebleau and Geneva. Retrieved from http:// 
De Negri, J. A., Salerno, M. S., \& Castro, A. B. (2005). Inovações, Padrões Tecnológicos e Desempenho das Firmas Industriais Brasileiras. In Inovações, Padrões Tecnológicos e Desempenho das Firmas Industriais Brasileiras (1st ed., p. 728). Brasília: IPEA.

Fabiani, S., \& Sbragia, R. (2014). Tax incentives for technological business innovation in Brazil: The use of the good law ??? Lei do Bem (Law no. 11196/2005). Journal of Technology Management and Innovation, 9(4), 53-63.

Garnica, L. A., Ferreira Junior, I., \& Fonseca, S. A. (2005). Relações empresauniversidade: Um estudo exploratório da Unesp no município de Araraquara SP. In Anais do XXV Enegep (CD-ROM). Porto Alegre.

IBGE. (2015). Pesquisa de Inovação 2014. http://doi.org/ISSN 0101-4234

IRI. (2016). 2016 GLOBAL R \& D Funding Forecast: A supplement to R\&D Magazine. R\&DMagazine.

IRI. (2017). GLOBAL R \& D FUNDING FORECAST A Supplement to R \& D Magazine. R\&D Magazine, (Winter 2017), 1-36. Retrieved from http://digital.rdmag.com/researchanddevelopment/2017_global_r_d_funding_for ecas

Mancini, R. F., \& Lorenzo, H. C. (2006). Potencialidades e Barreiras à cooperação Universidade, Empresa e Governo: $\mathrm{O}$ caso das micro e pequenas empresas do segmento médico-odontológico do município de Araraquara. In Anais do XXVI Enegep (CD-ROM). Fortaleza.

Marcovitch, J., Sbragia, R., Stal, E., \& Terra, J. C. C. (1991). Inovação tecnológica e incentivos fiscais. RAUSP-E (São Paulo), 26, 3-13.

MCTI. (2014). Lei do Bem: Utilização dos incentivos fiscais à inovação tecnológica (Ano-Base 2014).

MCTIP. (2015). Indicadores De Ciencia Y Tecnología Argentina 2015. Buenos Aires. Retrieved from http://indicadorescti.mincyt.gob.ar/documentos/indicadores_2015.pdf

Muller, P. (2003). Les Politiques Publiques. Paris: Presses Universitaires de France.

OECD. (1997). Manual de Oslo: Diretrizes para a Coleta e Interpretação de dados sobre Inovação Tecnológica. OCDE, Eurostat E Financiadora de Estudos $E$ Projetos, 184. http://doi.org/10.1787/9789264065659-es

OECD. (2015). OECD Science, Technology and Industry Scoreboard 2015: Innovation for growth and society.

RICYT. (2015). Estado de la Ciencia 2015. Retrieved from http://www.oei.es/salactsi/estado2015.pdf 
Sbragia, R. (1994). A experiência da Universidade de São Paulo. Revista Ciência.

Sbragia, R., \& Boscolo, R. (2011). Estratégia, Inovação e Desempenho: Uma análise da relevância da inovação de valor no desempenho das empresas. Revista Spacios, Espacios, 32(1), 35.

Sbragia, R., Kruglianskas, I. \& Arango-Alzate, T. (2001). Empresas Inovadoras no Brasil: Uma proposição de tipologia e características associadas. In Anais da Conferência Internacional da Altec - Associación Lation-lbero Americana de Gestión Tecnológica. Caracas/VE.

Segatto, A. P. (1996). Análise do Processo de Cooperação Tecnológica Universidade-Empresa: Um estudo exploratório. Universidade de São Paulo.

Terra, J.C.C. \& Sbragia, R. (1994). Incentivos fiscais para capacitação tecnológica: avaliação do custo de P\&D para a empresa a partir do Decreto-Lei no. 949 de 5 de outrubro de 1993. Revista de Administração, vol 29 (2), 105-109.

Unesco. (2017). Global Investments in R\&D (research and experimental development). UIS Fact Sheet 42.

Vasconcellos, E. P. G. (1979). Centralização x Descentralização: uma aplicação para laboratórios de pesquisa e desenvolvimento científico e tecnológico. Revista de Administração (FEA-USP), 14(2), 101-121.

WIPO. (2012). World Intellectual Property Indicators 2016. WIPO Economics and Statistics Series. http://doi.org/10.1016/0172-2190(79)90016-4 